\title{
Synthesis and characterization of indium tin oxide nanoparticles via reflux method
}

\author{
Sahebali Manafi*, Simin TaZikeh, Sedigheh Joughehdoust \\ Department of Engineering, Shahrood Branch, Islamic Azad University, Shahrood, Iran
}

\begin{abstract}
Synthesis of indium tin oxide (ITO) nanoparticles by reflux method without chlorine contamination at different $\mathrm{pHs}$, temperatures, solvents and concentrations has been studied. Indium chloride, tin chloride, water, ethanol and Triton X-100 were used as starting materials. Structure, size, surface morphology and transparency of indium tin oxide nanoparticles were studied by X-ray diffraction (XRD), Fourier transform infrared spectroscopy (FT-IR), scanning electron microscopy (SEM) and UV-Vis spectrophotometry. XRD patterns showed that $400{ }^{\circ} \mathrm{C}$ is the lowest temperature for synthesis of ITO nanoparticles because metal hydroxide does not transform to metal oxide in lower temperature. FT-IR results showed the transformation of hydroxyl groups to oxide. SEM images showed that $\mathrm{pH}$ is the most important factor affecting the nanoparticles size. The smallest nanoparticles $(40 \mathrm{~nm})$ were obtained at $\mathrm{pH}=8.8$. The size of crystallites was decreased by lowering of concentration $(0.025 \mathrm{M})$.
\end{abstract}

Keywords: reflux method; indium tin oxide; resistivity; transparency

\section{Introduction}

Transparent conductive oxides (TCO) have attracted attention for the past few years [1-4]. TCOs have been used widely in different industries, recently. The most widely used TCO is tin-doped indium oxide (ITO), which has high electrical conductivity and high transmittance in the visible light region [5]. It can absorb the light in infrared and ultraviolet regions. Electronic conduction in undoped indium oxide is due to oxygen vacancies. In tin doped indium oxide, $\mathrm{Sn}^{4+}$ substitutes for $\mathrm{In}^{3+}$, which gives rise to an additional electron in the conduction band [6]. Indium tin oxide is an ntype semiconductor [7] with a wide direct band gap $(3.5 \mathrm{eV}$ to $4.3 \mathrm{eV})$ [8]. It is widely used as a transparent conducting electrode in various optoelectronic devices such as solar cells [9], liquid crystal displays [7], organic light emitting diodes [10] and other flat displays, also for fuel cells [11] and gas sensors to detect combustible gases such as $\mathrm{CH}_{3} \mathrm{OH}, \mathrm{NO}_{2}, \mathrm{CCl}_{4}, \mathrm{CO}_{2}$ and $\mathrm{Cl}^{-}$[12-15]. ITO nanoparticles have been prepared by physical and chemical methods. The film deposited in the gas

\footnotetext{
*E-mail: a_manafi@iau-shahrood.ac.ir
}

containing hydrogen of $1 \%$ demonstrated almost flat temperature dependent resistivity and the lowest resistivity of $\approx 1.5 \times 10^{-4} \Omega \cdot \mathrm{cm}$ at room temperature [16].

Delacy et al. [17] reported the synthesis of ITO powders with varying morphologies using hydrothermal synthesis. Polyethylene glycol (PEG) 400 and sodium hydroxide $(\mathrm{NaOH})$ were used to promote the formation of non-spherical morphologies. Hydrothermal process requires high pressure and use of expensive equipment such as autoclave. Kyu-Jeon et al. [18] prepared ITO particles by using sol-gel and solvothermal methods. They found that the conductivity of the solvothermally prepared indium-tin-oxide/polyethylene terephthalate films was higher than that prepared by the sol-gel method.

Reflux is a suitable chemical method in synthesis of nanoparticles because it does not require high pressure and temperature. Also, the impurity can be eliminated by filtration and washing. In present study, ITO nanoparticles have been synthesized by reflux method and ultrasonic waves were used to homogenize the nanoparticles. Effects of changing temperature, $\mathrm{pH}$, concentration and solvent on morphology, size and resistivity was investigated. 


\section{Experimental}

Indium chloride tetrahydrate $\left(\mathrm{InCl}_{3} \cdot 4 \mathrm{H}_{2} \mathrm{O}\right.$, Aldrich $97 \%)$ and tin chloride $\left(\mathrm{SnCl}_{4}\right.$, Merck $99 \%$ ) as starting materials, Triton X-100 as surfactant, water and absolute ethanol as solvents, ammonia as precipitator were used to prepare ITO nanoparticles.

$\mathrm{InCl}_{3} \cdot 4 \mathrm{H}_{2} \mathrm{O}$ and $\mathrm{SnCl}_{4}$ were dissolved in ethanol, keeping the ratio of In:Sn equal to 90:10. Then 5 mmol Triton X-100 was added to the solution and stirred for 30 min till transparent solution was obtained. The ammonia solution $\left(\mathrm{NH}_{4} \mathrm{OH}\right)$ was dropped to the starting solution under stirring to keep a constant $\mathrm{pH}$ value. The solution was exposed to ultrasonic wave for $30 \mathrm{~min}$ to make it homogenous. Afterwards, the solution was refluxed at $75^{\circ} \mathrm{C}$ for $72 \mathrm{~h}$. The precipitate was collected by filtration then washed with distilled water and alcohol three times. After drying in ambient temperature overnight, the precursor was calcined at $400{ }^{\circ} \mathrm{C}$ for $1 \mathrm{~h}$. The ITO nanoparticles were obtained after cooling. ITO thin films were prepared by electron beam deposition method on glass substrate. Before deposition, glass substrates were ultrasonically cleaned in acetone, distilled water and ethanol, successively for $15 \mathrm{~min}$. Finally, they were dried with nitrogen gas. The pellets of ITO nanoparticles synthesized at different $\mathrm{pHs}$ filled in a copper crucible were used as evaporation sources. The evaporation chamber was evacuated to a base pressure of $4 \times 10^{-4} \mathrm{~Pa}$. During the deposition, the dynamic vacuum was kept around $1.5 \times 10^{-2} \mathrm{~Pa}$. During film growth, the chamber temperature was kept at $250{ }^{\circ} \mathrm{C}$ by a halogen lamp. The deposition rate during the deposition process was kept at $0.1 \mathrm{~nm} / \mathrm{s}$.

XRD patterns of ITO nanoparticles, prepared at various $\mathrm{pHs}$, solvents and temperatures, were recorded by the D8 Advance Bruker system using $\mathrm{CuK}_{\alpha}$ radiation $(\lambda=0.154056 \mathrm{~nm})$. The particles morphology was investigated by Cam Scan 2300 SEM. FT-IR spectra of the samples were recorded with a Bruker vector 22 working in a spectral range of $400 \mathrm{~cm}^{-1}$ to $4000 \mathrm{~cm}^{-1}$. The pellets were made of a mixture of $200 \mathrm{mg} \mathrm{KBr}$ dried at $120{ }^{\circ} \mathrm{C}$ and $3 \mathrm{mg}$ of the studied sample.

\section{Results and discussion}

XRD patterns of ITO nanoparticles prepared at different pHs are shown in Fig. 1(a-c). All of peaks were matched with diffraction data of a cubic structure of indium oxide (JCPDS Card No. 00006-0416) and no peaks from tin oxide could be observed. Doping of tin into indium oxide structure induces some changes in the diffraction patterns: the width of peaks increases and position of the peak is shifted to the lower angles [5]. Widths of peaks (FWHM) of the samples synthesized at different $\mathrm{pHs}$, temperatures and solvents are wider than the width of indium oxide (0.2) (Table 1). The ionic radius of tin is $0.69 \AA$, which is smaller than that of indium ( $\mathrm{r}=0.94 \AA$ ), which implies that tin could penetrate easily to the indium oxide lattice. The mean crystallite size (D) of the nanoparticles was also estimated using the Debye-Scherrer formula 1 as follows:

$$
D=\frac{0.9 \lambda}{\beta \cos \theta}
$$

where $\lambda, \beta, \theta$ are the $\mathrm{X}$-ray wavelength of radiation used $(\mathrm{CuK} \alpha=0.154056 \mathrm{~nm})$, the full width at half maximum (FWHM) of diffraction peak and the Bragg diffraction angle, respectively. The mean crystallite size at different $\mathrm{pHs}$, temperatures and solvents are shown in Table 1 . The existence of different natural amorphous tin oxides clusters $\left(\mathrm{Sn}_{\mathrm{i}} \mathrm{O}_{\mathrm{j}}\right)$ caused disturbances in the crystal lattice of indium tin oxide. It could convert the cubic phase of ITO to rhombohedral structure which couldn't be found in the synthesized powder in this study. It means the obtained tin oxide has a regular structure without any deficiency.

Fig. 1(d-f) shows XRD patterns of prepared indium tin oxide nanoparticles at different temperatures. Fig. 1d demonstrates the sample synthesis at $100{ }^{\circ} \mathrm{C}$. The sample consists of indium (III) hydroxide and tin (IV) hydroxide and the main peak is visible. It indicates that the temperature was not suitable for transformation of metal hydroxide to metal oxide. The precipitate of $\mathrm{InOOH}$ transformed to indium (III) hydroxide in the reflux process, which implies that the metastable $\mathrm{InOOH}$ developed and then transformed to cubic $\operatorname{In}(\mathrm{OH})_{3}$ 

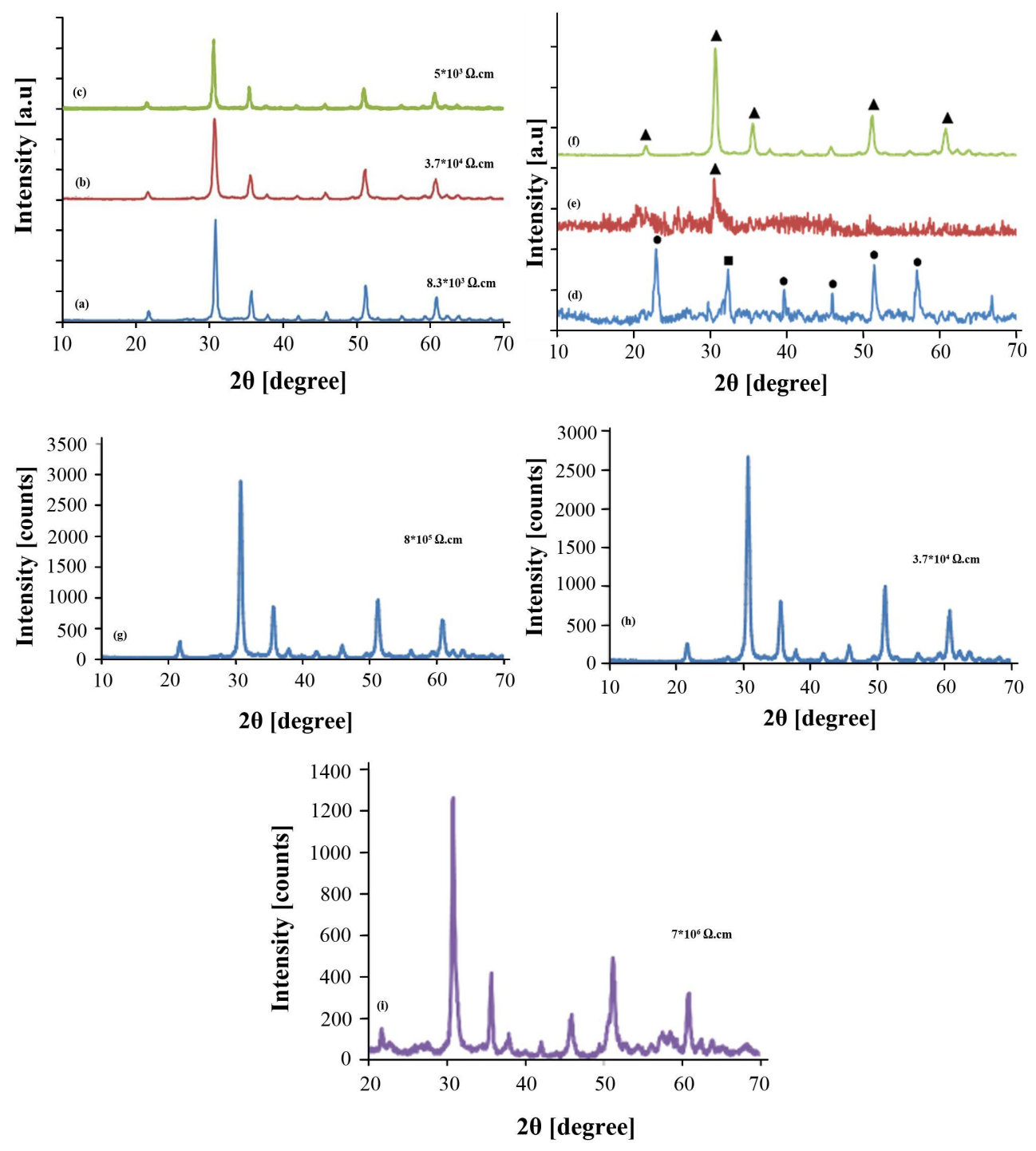

Fig. 1. The XRD patterns of ITO nanoparticles synthesized at different $\mathrm{pHs}$, (a) $\mathrm{pH}=6$, (b) $\mathrm{pH}=8.8$, (c) $\mathrm{pH}=10.5$; at different temperatures, (d) $100^{\circ} \mathrm{C}$, (e) $200{ }^{\circ} \mathrm{C}$, (f) $400{ }^{\circ} \mathrm{C}(\bullet$ indium hydroxide, $\bullet$ tin hydroxide, $\triangle$ ITO); synthesized in different solvents, (g) water and (h) ethanol; (i) synthesized in low concentration $(0.025 \mathrm{M})$.

during the reflux process. The intensity of the metal hydroxide peak decreases by increasing the temperature up to $200^{\circ} \mathrm{C}$, so the main indium oxide peak could be seen. Fig. 1f shows the XRD pattern of a sample synthesized at $400{ }^{\circ} \mathrm{C}$. All the peaks match with cubic structure of indium oxide and any metal hydroxide peaks are not observed.

Xie-Bin et al. [19] synthesized indium tin oxide nanoparticles by co-precipitation method at $800{ }^{\circ} \mathrm{C}$ but in present work ITO nanoparticles were synthesized at lower temperature without any specific atmosphere. Calcination temperature plays an important role in the size of nanoparticles. The size of particles increases by enhancing of temperature.

Fig. 1(g,h) shows XRD patterns of samples synthesized in different solvents $(\mathrm{pH}=8.8)$. Peak intensities, conductivities and dependence of peak position on solvent species have been 


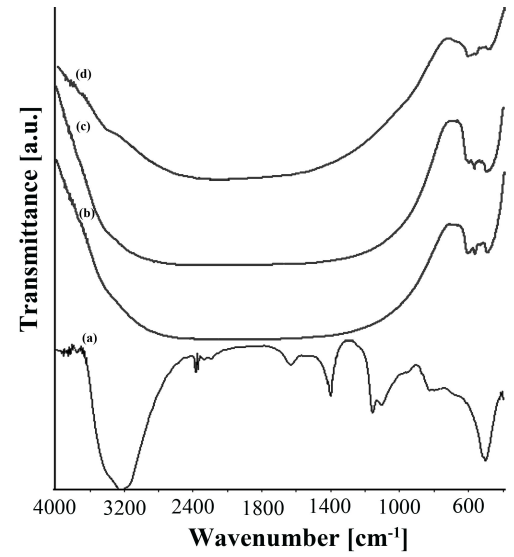

Fig. 2. FT-IR spectra of ITO nanoparticles synthesized at different $\mathrm{pHs}$, (a) precursor, (b) $\mathrm{pH}=6$, (c) $\mathrm{pH}=8.8$, (d) $\mathrm{pH}=10.5$.

Table 1. Mean crystallite size of ITO nanoparticles calculated by Scherrer formula from XRD patterns of samples synthesized at different $\mathrm{pHs}$, (a) $\mathrm{pH}=6$, (b) $\mathrm{pH}=8.8$, (c) $\mathrm{pH}=10.5$; at different temperatures, (e) $200{ }^{\circ} \mathrm{C}$, (f) $400{ }^{\circ} \mathrm{C}$; synthesized in different solvents $(\mathrm{g})$ water and (h) ethanol.

\begin{tabular}{cccc}
\hline $\begin{array}{c}\text { Mean } \\
\text { crystallite } \\
\text { size, D [nm] }\end{array}$ & $\begin{array}{c}\text { Width of } \\
\text { peak } \\
\text { [FWHM] }\end{array}$ & $\begin{array}{c}2 \theta \text { position } \\
{\left[{ }^{\circ} \text { ] }\right.}\end{array}$ & Sample \\
\hline \hline 53 & 0.3 & 30.8 & $\mathrm{a}$ \\
19 & 0.5 & 30.7 & $\mathrm{~b}$ \\
27 & 0.4 & 30.5 & $\mathrm{c}$ \\
99 & 0.27 & 30.6 & $\mathrm{e}$ \\
24 & 0.43 & 30.7 & $\mathrm{f}$ \\
33 & 0.36 & 30.8 & $\mathrm{~g}$ \\
20 & 0.48 & 30.7 & $\mathrm{~h}$ \\
\hline
\end{tabular}

considered. The main peak at $2 \theta=30.8^{\circ}$ is assigned to indium oxide according to JCPDS card number 00-001-0929. Nanoparticles synthesized in ethanol have a cubic structure (JCPDS Card No. 00-006-0416) according to the main peak position $2 \theta=30.7^{\circ}$. The peak intensities of synthesized samples become sharper when using water as a solvent in comparison with ethanol. In addition, the peak widths (FWHM) of nanoparticles synthesized in ethanol $(0.48 \mathrm{~nm})$ is broader than that of synthesized in water $(0.36 \mathrm{~nm})$. So, this result shows that using ethanol as a solvent results in introduction of higher amount of tin in the structure of indium oxide than in the case of water solution. Fig. 1h shows XRD pattern of samples synthesized in low concentrated solution $(0.025 \mathrm{M})$. Position of main peak is $2 \theta=30.8^{\circ}$ (JCPDS Card No. 00-001-0929) and no tin oxide peak is observed.

Fig. 2 shows FT-IR spectra of the precursor and samples synthesized at different $\mathrm{pHs}$ in the range of $400 \mathrm{~cm}^{-1}$ to $4000 \mathrm{~cm}^{-1}$. The presence of $\mathrm{OH}$ in the precursor is revealed at three modes of vibration at $3000 \mathrm{~cm}^{-1}$ to $3600,1620 \mathrm{~cm}^{-1}$ to $1630 \mathrm{~cm}^{-1}$ and $832 \mathrm{~cm}^{-1}$ to $837 \mathrm{~cm}^{-1}$. These vibrations were not observed in the synthesized samples which indicated the transformation of oxides. The bands at $1160 \mathrm{~cm}^{-1}$ and $1405 \mathrm{~cm}^{-1}$, assigned to terminal hydroxyl group of $\operatorname{In}(\mathrm{OH})$ and hydroxyl group of $\mathrm{Sn}(\mathrm{OH})$, were not observed which indicates that all of the hydroxyl groups transformed into oxide groups. Two vibrations at $665 \mathrm{~cm}^{-1}$ and $710 \mathrm{~cm}^{-1}$ indicate $\mathrm{Sn}-\mathrm{O}$ or O-Sn-O and $\mathrm{Sn}-\mathrm{O}-\mathrm{Sn}$ bonds, respectively. The sharp band at $492 \mathrm{~cm}^{-1}$ to $520 \mathrm{~cm}^{-1}$ is related to In-O-In. No band due to impure materials in all the samples synthesized at different $\mathrm{pHs}$ was observed.

Fig. 3(a-c) shows SEM images of indium tin oxide nanoparticles synthesized in different conditions. The nanoparticles have spherical morphologies and changing size at different pHs. By slow dropping of ammonia to the solution during stirring, the ammonia diffuses fast into the solution and the reaction occurs extensively, which forms many initial nuclei. The mean size of the nanoparticles synthesized at $\mathrm{pH}=6$ is equal to $63 \mathrm{~nm}$. The mean size of particles decreased to $50 \mathrm{~nm}$ by increasing $\mathrm{pH}$ to 8.8. However, the mean size of particles increased to $60 \mathrm{~nm}$ at $\mathrm{pH}=10.5$. Isoelectric point $\mathrm{pH}$ of indium hydroxide is in the range of 4.8 to 10 [20]. In fact, the electrical charge of indium hydroxide is zero $\left(\operatorname{In}(\mathrm{OH})_{3}^{0}\right)$ in this range. Therefore, due to absence of electrical expulsion between particles, they gather together and form bigger particles. The particles size of tin decreases with increasing $\mathrm{pH}$ from 6 to 9, then it stays constant without any changes [21]. In the range of $\mathrm{pH}=6$ to 9 , due to higher hydrolysis speed of tin 


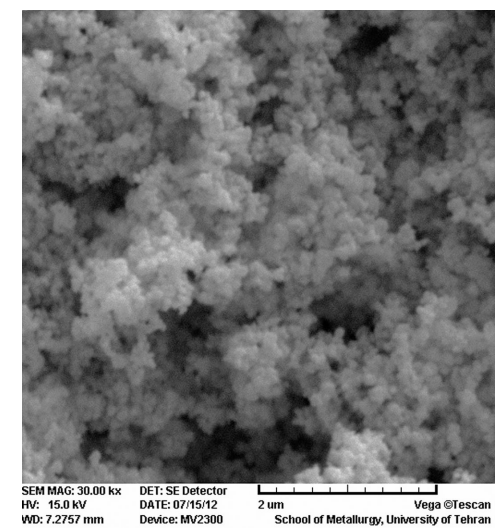

(a)

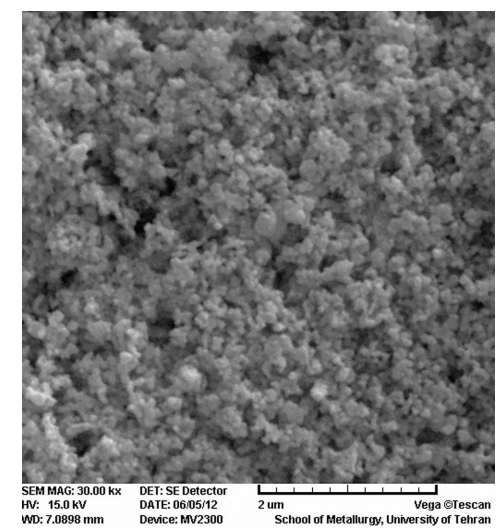

(c)

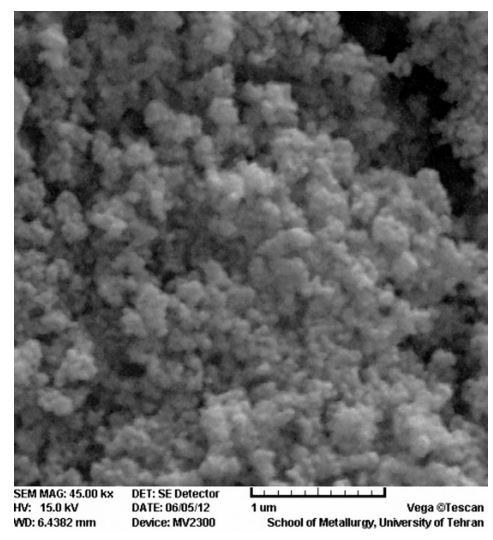

(e)

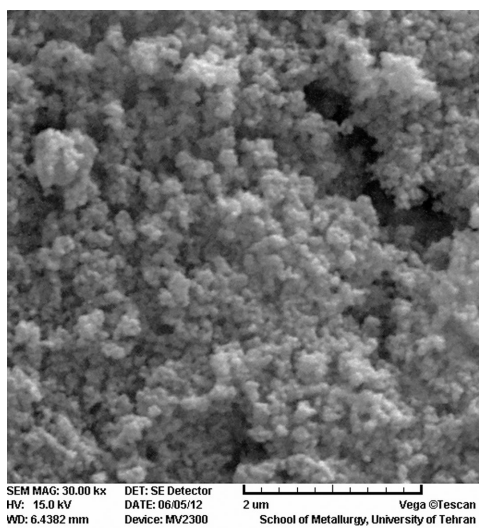

(b)

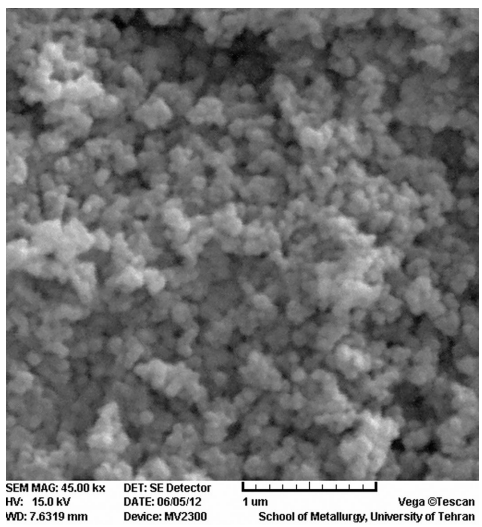

(d)

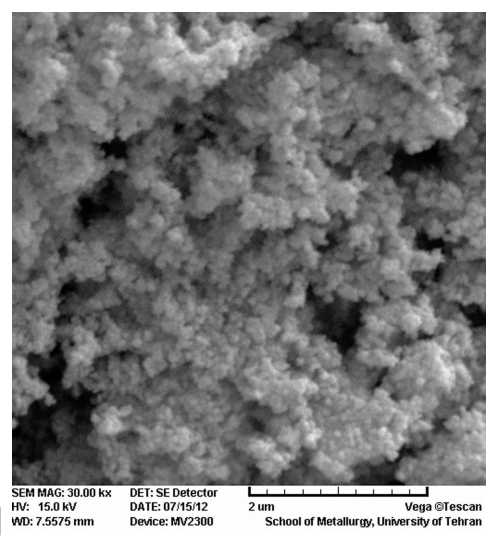

(f)

Fig. 3. SEM images of ITO nanoparticles synthesized at different $\mathrm{pHs}$, (a) $\mathrm{pH}=6$, (b) $\mathrm{pH}=8.8$, (c) $\mathrm{pH}=10.5$; in different solvents, (d) water and (e) ethanol; (f) synthesized in low concentration $(0.025 \mathrm{M})$.

than of indium [22], the speed of decreasing the size of tin is higher than the speed of increasing indium hydroxide size. The smallest particles have been produced at $\mathrm{pH}=8.8$. When $\mathrm{pH}$ increases, particles size of tin is constant but indium hydroxide grows again.
Fig. 3(d,e) shows SEM images of samples synthesized in water and ethanol as a solvent. The particle size of ITO increased when water was used as the solvent, but decreased with ethanol. The tendency of agglomeration of nanopowders decreased when using an organic solvent (ethanol) instead of 
water, and smaller crystallites were formed. Thin films coated with ITO synthesized in ethanol have lower resistance than thin films coated with ITO synthesized in water, because the samples with cubic structure have higher conductivity than the rhombohedral ones which may be due to less deficiencies in the cubic crystal lattice.

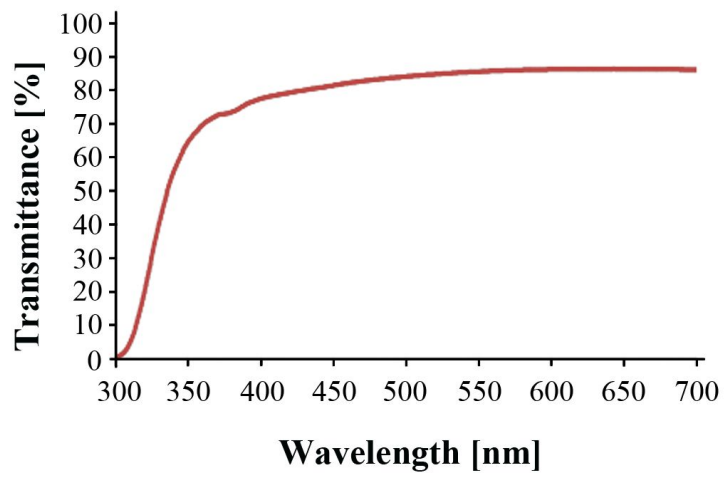

Fig. 4. Optical transmission spectra of ITO nanoparticles synthesized at $\mathrm{pH}=8.8$.

The mean size of nanoparticles with spherical morphologies is $40 \mathrm{~nm}$ (Fig. 3f). The mean size of nanoparticles decreases with the concentration of solution. In fact, the ionic strength of the system decreases at lower concentration [23]. When the ionic ability is less, the flocculation process is slower, therefore the thickness of the ionic layer around the particles, and, as a result, the size of particles is decreased.

Kim et al. [24] reported total conductive resistance depending on contact resistance. Therefore at $\mathrm{pH}=8.8$ when the particle size decreased, resistivity increased in comparison with $\mathrm{pH}=10.5$ and 6 because the contact point increased. Fig. 4 shows the transmittance of ITO thin film $(\mathrm{pH}=8.8)$ at the wavelength region of $300 \mathrm{~nm}$ to $700 \mathrm{~nm}$. The result shows that the film is highly transparent over the visible regions (about $85 \%$ ) and it is very suitable for usage in optoelectronic devices such as solar cells, organic electroluminescent devices, functional glasses, and thermal mirrors [25].

\section{Conclusions}

Indium tin oxide nanoparticles have been synthesized by reflux method. No requirements of high temperature and special atmosphere have been imposed. FT-IR results revealed transformation of hydroxyl groups into oxide. XRD patterns show that $400{ }^{\circ} \mathrm{C}$ is the lowest temperature for synthesis of ITO nanoparticles because metal hydroxide does not transform into metal oxide at lower temperature. Moreover, ITO nanoparticles have a cubic structure due to absence of neutral clusters of different tin oxides $\left(\mathrm{Sn}_{\mathrm{i}} \mathrm{O}_{\mathrm{j}}\right)$ and there is no disturbance in the structure. SEM images show that $\mathrm{pH}$ is the most important factor affecting nanoparticles size, (smallest nanoparticles ( $40 \mathrm{~nm}$ ) have been obtained at $\mathrm{pH}=8.8$ ). The XRD and SEM studies revealed that solvent type and concentration affect nanoparticles structure and their resistivity. The size of nanoparticles synthesized in ethanol is smaller than the ones obtained in water because the distance between ITO crystallites is larger when ethanol is used as a solvent. The size of crystallites has been decreased by lowering of concentrations $(0.025 \mathrm{M})$.

\section{References}

[1] Gao Y., Zhao G., Duan Z., Ren Y., Mater. Sci.Poland, 32 (2014), 66.

[2] LiU Y., ŠTeFAnić G., RATHOUSKy J., HAYden O., Bein T., Fattakhova-Rohlfing D., Chem. Sci., 3 (2012), 2367.

[3] Domaradzki J., Kaczmarek D., DrabczyK K., PANEK P., Mater. Sci.-Poland, 33 (2015), 363.

[4] Rajabi N., Heshmatpour F., Malekfar R., Mater. Sci.-Poland, 32 (2014), 102.

[5] Shi J., Shen L., Meng F., Liu Z., Mater. Lett., 182 (2016), 32.

[6] Pohl A., Dunn B., Thin solid films, 515 (2006), 790.

[7] Song S., Yang T., LiU J., Xin Y., Li Y., Han S., Appl. Surf. Sci., 257 (2011), 7061.

[8] Qiang X.B., Kang F.R., BIN Y., Yong D., Trans. Nonferrous Met. Soc. China, 20 (2010), 643.

[9] ZHANG D., TAVAKOliYaraki A., Wub Y., vaN SWAAiJ R.A., ZEMAn M., Energy Procedia, 8 (2011), 207.

[10] Zhang H., Ye F., LiU L., Xu H., Sun C., J. Alloys Compd., 504 (2010), 171.

[11] Mehta V., Cooper J., J. Power Sources, 114 (2002), 32.

[12] Xu S., Shi Y., Sens. Actuat. B., 143 (2009), 71.

[13] Patel N.G., Patel P.D., Vaishnav V.S., Sens. Actuat. B., 96 (2003), 180. 
[14] Patel N.G., Makhija K.K., Panchal C.J., Sens. Actuat. B., 21 (1994), 193.

[15] Patel N.G., Makhija K.K., Panchal C.J., Dave D.B., VaishnaV V.S., Sens. Actuat. B., 23 (1995), 49.

[16] Luo S., OKada K., KohiKi S., Tsutsui F., ShIMOOKA H., Shoji F., Mater. Lett., 63 (2009), 641.

[17] Delacy G., Lacey S., Zhang D., Valdes E., HOANG K., Mater. Lett., 117 (2014), 108.

[18] KyU-Jeon M., Kang M., Mater. Lett., 62 (2008), 676.

[19] Xie-Bin Z., TaO J., Guan-Zhou Q., Bai-Yun H., Trans. Nonferrous Met. Soc. China, 19 (2009), 752

[20] Wood S., SAmson I., Ore. Geol. Rev., 28 (2006), 57.

[21] Jiang L., Sun G., Zhou Z., Sun S., Wang Q., Yan S., Li H., Tian J., Guo J., Zhou B., Xin Q., J. Phys. Chem. B., 109 (2005), 8774.
[22] YU D., YU W., WANG D., QIAN Y., Thin solid films, 419 (2002), 166.

[23] Thomas HE Y., Wang J., Tokunaga T., J. Nanapart. Res., 10 (2008), 321.

[24] Kim K.Y., Park S.B., Mater. Chem. Phys., 86 (2004), 210.

[25] Silva G.M, Faria DE E.H., NASSAR E.J., CiUfFI K.J., CAlefi P.S., Quim. Nova., 35 (2012), 473.

Received 2017-03-05 Accepted 2018-01-22 